\title{
Knowing Customers Better: An Experimentation of Twit Marketing in the e-Commerce Industry
}

\author{
http://dx.doi.org/10.3991/ijac.v7i2.3867 \\ H.A. ALTURKI, A. FAYYOUMI \\ Al Imam Mohammad ibn Saud Islamic University (IMSIU), Riyadh, Saudi Arabia
}

\begin{abstract}
Internet gives incredible opportunities for companies to learn about their consumers and provides different channels for marketing. Otlobli.com website (an ecommerce company established in Saudi Arabia), uses different channels, such as: Google AdWords, newspaper website banners, official thread on a famous online forum and, Twitter. A marketing tool has been developed to enhance the effectiveness of marketing on Twitter. This research investigates the impact of the developed system. Website access from these various channels was examined, in addition to the number of visitors who have completed an order. Results showed that the tool caused around $49 \%$ increase in the number of visits from Twitter, and comparatively, a good percentage of them completed an order.
\end{abstract}

Index Terms-Twit Marketing, e-Marketing, e-Commerce, Organizational Learning

\section{INTRODUCTION}

The fundamental thing marketing professionals want is to learn about customers. Internet gives incredible opportunities for companies to learn about their consumers. In the knowledge economy, knowledge is increasingly considered a critical factor for organization's success and a source of its competitive advantage and value creation [1], [2]. The development and widespread use of information technologies are fostering the revolution of means used to access, and share information. In particular, internet technologies are literally facilitating individual and organizational access to information they need and utilize these information as needed. This new economy has introduced a new lexicon in which knowledge capital, intellectual capital, learning organizations, intangible assets, and human capital describe new forms of economic value [3]. The potential usefulness of information technologies is well recognized. In fact, these technologies are considered critical part of modern life. Their importance has rapidly increased with time on a personal and organizational levels, especially with the development of the Internet and electronic commerce. Now a days, the role of IT is more essential rather that supportive. It helps in building organizational strategies by providing new market opportunities, products, and customers [4].

Social media have revolutionized the 21 st century. The proliferation of social media has exceeded expectations. It is globally available on numerous devices, including mobile devices, which assist users to access these services any time. With social networking sites, such as Twitter and Facebook, people are connected with each other and can share and exchange messages, media, and news easily. Social media have become essential tools for individuals, companies, and governments. The influence of social network sites is critical and far-reaching, affecting personal lives, governments, and business, particularly in terms of marketing strategies, sales, and new opportunities for existing and start-ups. Lately, marketing is more significant than ever, with many channels available that can be used to reach customers and optimally market goods and services. Marketing has been performed directly or indirectly via multiple traditional channels including TV, newspapers, banners, or other print media. However, the introduction of the World Wide Web has changed the concept of marketing, with new channels that supersede traditional ones.

This study aims to develop and experiment a tool for marketing on Twitter for one of the e-commerce sites, Otlobli.com, a company in Saudi Arabia that handles the purchasing and payment processes of online products and ensures the delivery of these items to local addresses.

\section{TWITTER FOR MARKETING}

Social media has influenced advertisements and marketing strategies. Recently, there has been an interest in the used of social media in marketing. Several companies are already using social networking sites to support the creation of brand communities [5] or for marketing research in the context of netnography [6].

Twitter, which was launched in 2006 , enables users to send and read short messages limited to 140 characters, known as "tweets". For some authors referred to Twitter as an information sharing tool rather than a social network platform [7], [8], [9]. Regardless of its classification, Twitter has grown exponentially, reaching 200 million users and recording over 30 billion messages in only five years [10].

Twitter is one of the most known and accessed social networking site in Saudi Arabia. Twitter penetration keeps breaking records, placing Saudi Arabia on top Twitter user penetration per internet capita, increasing its user base by $45 \%$ in 2013 with more than 5 million active users, $73 \%$ of them access Twitter via mobile (http://www.thesocialclinic.com). Most users of Twitter share or report news, exchange information, discuss different opinions and political and social interests, and campaigning for or against certain people, companies, or governments [11].

In addition of the role Twitter plays at different levels; for instance, at the political level as in the Egyptian revolution in 2011 [12] on one hand, and on the business level as in word of mouth marketing on the other hand [13], Twitter can be considered an effective platform for mar- 
keting and public relations. Marketing strategies on Twitter can be, interactive or reactive. The former is using Twitter "to provide a highly interactive one-to-many information channel, using, and a combination of retweets, hyperlinks, and hashtags to promote positive messages, especially by independent influential individuals" [14]. Where the latter is "using Twitter as a service recovery channel to respond to customer complaints - both those made directly to the organization, or those discovered by monitoring the Twitter feed" [13]. Twitter can also provide easy access to information for those to who it is most relevant or interesting, by pushing users to an internal web site on one hand, and companies can listen to/influence consumers' opinions" [15].

Otlobli (otlobli.com) is a small Saudi online company that handles the purchasing, payment and delivery processes of online products from other e-commerce sites and ensures the delivery of purchased items to local addresses. They use different channels to market their services many of which are performed manually. Some examples of these channels are Twitter, Google AdWords, newspaper website banners, and advertisements in online forums.

The company never tried a semi-automated mechanism with Twitter to market its services. Therefore, we developed and experimented a Twit Marketing tool, which is discussed in section III, for advertising Otlobli and we compared it to the other techniques. Results are presented in section $\mathrm{V}$.

\section{TOOL DEVElOPMENT FOR TWIT MARKETING}

Lots of questions being asked by people on Twitter either were not receiving answers, or were receiving useless answers. Businesses are having a hard time finding ways to interact with Twitter users. There are various tools available in the market, such as: InboxQ (inboxq.com), Twitter Keyword Tracker (twtrland.com), and Tweetbeep (tweetbeep.com). However, most of the available solutions are limited to basic keyword searches; and none of these tools provide an automatic replies to the tweets that found to be related to a specific topic. A tool that helps increase the likelihood that information seekers will get good answers to their questions has been developed.

The web-based tool can be used to collect everything about a specific topic based on the keywords related to the topic (e.g. product and organization). We can then reply automatically to all tweets collected with a pre-defined reply. This tweet can also be sent to a group of people who are potentially interested in buying online or looking for some help in this matter, system architecture is shown in Figure I. In particular, the web-based tool is used in two steps. First, creating categories and defining keywords that can be used to collect business related tweets. Second, replying to the collected tweets in which multiple tweets can be selected from the list and a single reply can be sent from company's Twitter accounts. Automatic replies has been defined to be sent immediately to tweets collected under a specific category. The tool also provides a statistical report on all tweets, including the retweets, accounts been tweeted ...etc.

One important consideration in the development of the tool is the ethical issue. The tool can be used to help information seekers. But also can be misused to harm people or companies by sending messages to people who do not wish to receive them. To avoid any ethical violation, we manually made sure that tweets sent by the system reaches only people who are interested in such information and avoid any random push of messages.

\section{Methodology}

As mentioned previously, Otlobli.com marketing partner used to send tweets manually to potential customers who ask about buying online or related information. We conducted an experimentation at the company to study the impact of Twit Marketing on website visitors and number of orders made.

The research have gone through two main stages. First, in collaboration with Otlobli management, we manually listed 35 keywords or hashtags that indicates potential customers. For instance, one of the detected hashtags was related to a negative feedback regarding another online company that provides similar service. Second, the monitoring period of three weeks for collecting interesting tweets and subsequently sending a 113-character tweet that summarizes Otlobli's main service and the link to the web site.

$$
\text { سوى } 4 \text { خظّو ات سريعة. للطلب من المع و الماركات العالمية بكل سهولة و لايتطلب }
$$

The accounts are configured to send one tweet every five minutes per account, enabling us to send 100 tweets

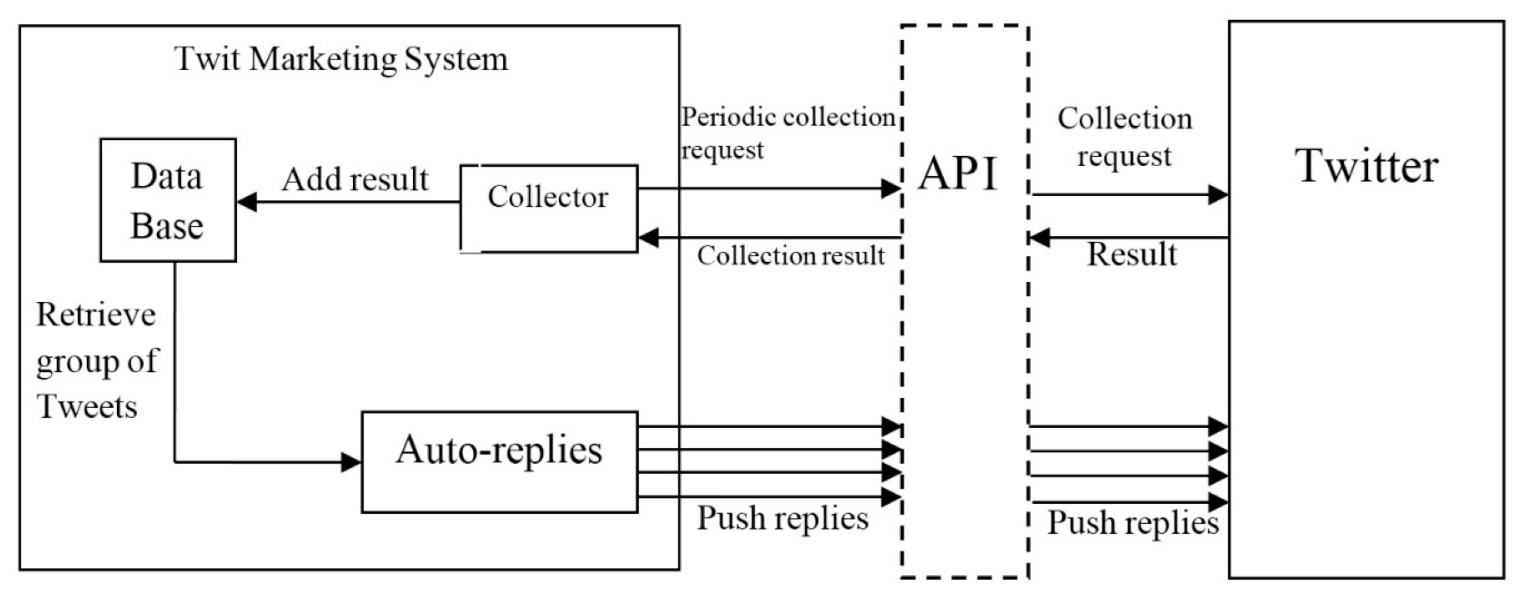

Figure 1. Web-based System Architecture 
every five minutes. Throughout the three-week period, collected tweets will be reviewed (manually) and unrelated tweets were excluded.

Later on, Otlobli management provided detailed statistics about the number of visits, including statistics on who completed an order, allowing us to present accurate results. In addition, we got analytics distributed on the channels used for marketing, for example, Google Adwords, normal banners on certain websites, and publishing official advertisement threads on an online forum. These statistics can be found via Google Analytics, a comprehensive, accurate, and trusted third-party tool.

\section{FINDINGS}

An experiment has been conducted to measure the effectiveness of marketing via Twitter and it has gone through two stages, hunting potential customers' tweets, and then replying to those tweets and measure the impact on the number of visitors and completed orders. During the three-week stage, many Arabic tweets $(n=567)$ were captured, examples are shown in Table I. The majority of these tweets $(n=432)$ were related to one hashtag in which users expressed their dissatisfaction of dealing with a competitor company providing similar services. Obviously, this number of related tweets is difficult to capture manually and will require a lot of time and effort.

As stated previously, different channels are used to market the Otlobli.com website, these are: Google AdWords, newspaper website banners, official thread on a famous online forum and Twitter. However, to investigate the accurate value of the developed system, we differentiate between the manual/traditional marketing, and the semi-automated marketing using the developed tool. Website access from these various channels was examined, in addition to the number of visitors who have completed an order. Data has been gathered captured over a four-day period from Google Analytics are presented in Table III. An explanation of the metrics is provided in Table II.

Manual/traditional marketing on Twitter is conducted through a company that specializes in marketing on Twitter. The company undertakes several activities, such as replying to all questions forwarded to the Otlobli account on Twitter, following new accounts to indirectly inform them about the Otlobli account, promoting tweets in active hashtags, tweeting daily using the official Otlobli accounts on Twitter, and re-tweeting some Otlobli account tweets. The average of visits that used to come from Twitter, using the traditional marketing method, were around the 550 visits for a similar four-day period.

After the start of the experimentation (replying to the collected tweets), the number of visits to the website raised to 822 visits in the four-day period. We can therefore conclude that the additional visits were because of the replies sent automatically through the developed system.

\section{CONCLUSION}

Google AdWords is clearly the best marketing channel based on all the metrics (visits and orders completed). It was the cause of most of the visits $(79 \%)$ to Otlobli.com website during the four-day period. However, only $2.91 \%$ of those visitors made completed order, see Table IV. On the other hand, Twitter followed Google AdWords in rank. Twitter caused 822 visits, $(17 \%)$ of total visits.
TABLE I.

SAMPLE OF CAPTURED TWEETS

\begin{tabular}{|c|c|}
\hline Translated Tweets & Original Arabic Tweet \\
\hline $\begin{array}{l}\text { "I would love to try buying } \\
\text { online" }\end{array}$ & "ودي اجرب يوم اشتري من النت، \\
\hline "How can I buy online - ?" & "وشلون اشتري من النت؟، \\
\hline $\begin{array}{l}\text { "Please may you explain how I } \\
\text { can buy online, I would love to } \\
\text { try this method but I don't know } \\
\text { how" }\end{array}$ & 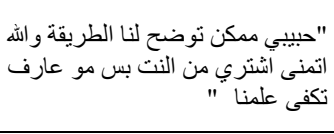 \\
\hline
\end{tabular}

TABLE II.

NUMBER OF VISITORS WHO COMPLETED AN ORDER

\begin{tabular}{|c|c|c|c|c|}
\hline Metric & \multicolumn{4}{|c|}{ Description } \\
\hline Source/Medium & \multicolumn{4}{|c|}{$\begin{array}{l}\text { Type of channel the visitors used to access the } \\
\text { website. }\end{array}$} \\
\hline Sessions & \multicolumn{4}{|c|}{ Number of visits } \\
\hline$\%$ New Sessions & \multicolumn{4}{|c|}{$\begin{array}{l}\text { Percentage of new visitors from the total } \\
\text { number of visits or the number of visitors } \\
\text { who had not visited Otlobli.com website since } \\
\text { a month ago }\end{array}$} \\
\hline New Users & \multicolumn{4}{|c|}{$\begin{array}{l}\text { Number of new visitors from the total number } \\
\text { of visitors }\end{array}$} \\
\hline $\begin{array}{l}\text { Order Done (Goal } 3 \\
\text { Conversion Rate) }\end{array}$ & \multicolumn{4}{|c|}{$\begin{array}{l}\text { Percentage of visitors who submit and pay for } \\
\text { a specific order on Otlobli.com from the total } \\
\text { number of visits. }\end{array}$} \\
\hline $\begin{array}{l}\text { Order Done (Goal } 3 \\
\text { Completions) }\end{array}$ & \multicolumn{4}{|c|}{$\begin{array}{l}\text { Number of visitors who submit and pay for a } \\
\text { specific order on Otlobli.com from the total } \\
\text { number of visits. }\end{array}$} \\
\hline \multicolumn{5}{|c|}{$\begin{array}{c}\text { TABLE III. } \\
\text { RESULTS FROM GOOGLE ANALYTICS }\end{array}$} \\
\hline \multicolumn{2}{|c|}{ Source / Medium } & Sessions & $\begin{array}{l}\text { \% New } \\
\text { Sessions }\end{array}$ & New Users \\
\hline \multicolumn{2}{|l|}{ Google AdWords } & 3774 & $71.86 \%$ & 2712 \\
\hline \multicolumn{2}{|l|}{ Al-Jazirah.com } & 25 & $52.00 \%$ & 13 \\
\hline \multicolumn{2}{|l|}{ Almokhtsar.com } & 75 & $92.00 \%$ & 69 \\
\hline \multicolumn{2}{|c|}{ Forum.hawaaworld.com } & 43 & $72.09 \%$ & 31 \\
\hline \multicolumn{2}{|c|}{ m.forum.hawaaworld.com } & 28 & $42.86 \%$ & 12 \\
\hline \multicolumn{2}{|l|}{ Twitter } & 822 & $51.70 \%$ & 425 \\
\hline
\end{tabular}

TABLE IV.

NUMBER OF VISITORS WHO COMPLETED AN ORDER

\begin{tabular}{lll}
\hline \multicolumn{1}{c}{ Source/Medium } & $\begin{array}{c}\text { Order Done } \\
\text { (Conversion) }\end{array}$ & $\begin{array}{c}\text { Order Done } \\
\text { (Completions) }\end{array}$ \\
\hline Google AdWords & $2.91 \%$ & 110 \\
Twitter & $1.88 \%$ & 5 \\
\hline
\end{tabular}

More importantly, the percentage of visitors who actually placed orders is not substantial between Google AdWords and Twitter marketing channels. Since $2.91 \%$ of visitors through Google AdWords placed actual orders, $1.88 \%$ of visitors through Twitter submitted complete orders. The number of visits from Twitter before using the marketing tool was about 550 visits and the tool caused the increase of about $49 \%$ getting 822 visits in total. 


\section{REFERENCES}

[1] E. Coakes \& S. Clarke. The Encyclopaedia of Communities of Practice in Information and Knowledge Management, London: Idea Group Inc.

[2] S. Dasgupta. Encyclopedia of Virtual Communities and Technologies. Idea Group Publishing; Pck edition. 2005.

[3] N. Bontis. Assessing Knowledge Assets: A Review of the Models Used to Measure Intellectual Capital. International Journal of Management Review, Vol. 3, No. 1, March, pp 41-60, 2001. http://dx.doi.org/10.1111/1468-2370.00053

[4] J. Ward and P. M. Griffiths, Strategic planning for information systems, 2nd ed. Chichester; New York: Wiley, 1996.

[5] A. M. Muniz and T. C. O'Guinn, "Brand community," Journal of Consumer Research, 27(4), 412-432, 2001. http://dx.doi.org/ $\underline{10.1086 / 319618}$

[6] R. V. Kozinets, "The field behind the screen: Using netnography for marketing research in online communities," Journal of Marketing Research, 39(1), 61-72, 2002. http://dx.doi.org/10.1509/ jmkr.39.1.61.18935

[7] M. Cataldi, L. Di Caro, and C. Schifanella, "Emerging topic detection on Twitter based on temporal and social terms evaluation," in Proceedings of the Tenth International Workshop on Multimedia Data Mining (MDMKDD '10) ACM, New York, NY, USA, 2010.

[8] C. Lee, H. Kwak, H. Park, and S. Moon, "Finding in uentials based on the temporal order of information adoption in Twitter," in 19th World-Wide Web (WWW) Conference, Raleigh, North Carolina, 2010.

[9] W.V. Osch, and M. Avital, "Generative collectives," ICIS 2010 Proceedings, Paper 175, 2010.

[10] B. Petit, "Five Years of Twitter," Gaston Gazette online, 2011.

[11] A. Java, X. Song, T. Finin, and B. Tseng, "Why we Twitter: understanding microblogging usage and communities," in Proceedings of the Ninth WEBKDD and First SNA-KDD Workshop on Web Mining and Social Network Analysis, pp.56-65, 2007.
[12] K. Fahim, "Protesters in Egypt defy ban as government cracks down," The New York Times Online, 2011.

[13] B. J. Jansen, M. Zhang, K. Sobel, and A. Chowdury, "Twitter Power: Tweets as Electronic Word of Mouth," JOURNAL OF THE AMERICAN SOCIETY FOR INFORMATION SCIENCE AND TECHNOLOGY, vol. 60, pp. 2169-2188, 2009. http://dx.doi.org/10.1002/asi.21149

[14] S. Burton and A. Soboleva, "Interactive or reactive Marketing with Twitter," Journal of Consumer Marketing, vol. 28, pp. 491499, 2011. http://dx.doi.org/10.1108/07363761111181473

[15] M. Bulearca and S. Bulearca, "Twitter: a Viable Marketing Tool for SMEs?" Global Business and Management Research: An International Journal, vol. 2, pp. 296-309.

\section{AUTHORS}

H. Al Turki has completed his Master degree in Information Systems. He has industrial experiences and in different roles in Information Technology, mainly in banking and telecom industry. He also interested with Twitter applications (h.alturki80@gmail.com).

A. Fayyoumi is an Assistant Professor of Information Systems at the College of Computer and Information Sciences. His research focuses on e-Learning, online exam systems, knowledge management, and e-Business. He is the head of the Scientific Advisory Committee responsible for improving courses contents according to international scientific and quality standards, and a member of the Quality Assurance Committee responsible for ABET accreditation. He also provides different consultation services to various institutions (a.fayyoumi@gmail.com)

Submitted, 12 May 2014. Published as resubmitted by the authors on 08 June 2014. 